\title{
Thyroid vascularity and blood flow are not dependent on serum thyroid hormone levels: studies in vivo by color flow doppler sonography
}

Fausto Bogazzi, Luigi Bartalena, Sandra Brogioni, Alessandro Burelli, Luca Manetti, Maria Laura Tanda, Maurizio Gasperi and Enio Martino

Dipartimento di Endocrinologia e Metabolismo, Ortopedia e Traumatologia, Medicina del Lavoro, University of Pisa, Pisa, Italy

(Correspondence should be addressed to E Martino, Dipartimento di Endocrinologia e Metabolismo, Ortopedia e Traumatologia, Medicina del Lavoro, Università di Pisa, Ospedale di Cisanello, Via Paradisa, 2, 56122 Pisa, Italy)

\begin{abstract}
Objective: Thyroid blood flow is greatly enhanced in untreated Graves' disease, but it is not known whether it is due to thyroid hormone excess or to thyroid hyperstimulation by TSH-receptor antibody. To address this issue in vivo patients with different thyroid disorders were submitted to color flow doppler sonography (CFDS).

Subjects and methods: We investigated 24 normal subjects, and 78 patients with untreated hyperthyroidism (49 with Graves' hyperthyroidism, 24 with toxic adenoma, and 5 patients with TSH-secreting pituitary adenoma (TSHoma)), 19 patients with thyrotoxicosis ( 7 with thyrotoxicosis factitia, and 12 with subacute thyroiditis), 37 euthyroid patients with goitrous Hashimoto's thyroiditis, and 21 untreated hypothyroid patients with Hashimoto's thyroiditis.

Results: Normal subjects had CFDS pattern 0 (absent or minimal intraparenchimal spots) and mean intraparenchimal peak systolic velocity (PSV) of $4.8 \pm 1.2 \mathrm{~cm} / \mathrm{s}$. Patients with spontaneous hyperthyroidism due to Graves' disease, TSHoma, and toxic adenoma had significantly increased PSV $(P<0.0001, P=0.0004, P<0.0001$ respectively vs controls $)$ and CFDS pattern. Patients with Graves' disease had CFDS pattern II (mild increase of color flow doppler signal) in $10(20 \%)$ and pattern III (marked increase) in 39 cases $(80 \%)$. Mean PSV was $15 \pm 3 \mathrm{~cm} / \mathrm{s}$. Patients with toxic adenoma had CFDS pattern I (presence of parenchymal blood flow with patchy uneven distribution) in $2(8 \%)$, pattern II in $16(70 \%)$ and pattern III in $5(22 \%)$. Mean PSV was $11 \pm 2.4 \mathrm{~cm} / \mathrm{s}$. Patients with TSHoma showed CFDS pattern I in one case $(20 \%)$ and pattern II in $4(80 \%)$. Mean PSV was $14.8 \pm 4.2 \mathrm{~cm} / \mathrm{s}$. Patients with thyrotoxicosis had normal PSV $(4.2 \pm 1.1 \mathrm{~cm} / \mathrm{s}$ in subacute thyroiditis, $4 \pm 0.8 \mathrm{~cm} / \mathrm{s}$ in thyrotoxicosis factitia, $P=$ not significant vs controls) and CFDS pattern 0 . Untreated euthyroid patients with goitrous Hashimoto's thyroiditis had CFDS pattern 0, and mean PSV $(4.3 \pm 0.9 \mathrm{~cm} / \mathrm{s} ; \quad P=$ not significant vs controls). Untreated hypothyroid patients with goitrous Hashimoto's thyroiditis had CFDS pattern I in 14 cases $(67 \%)$, pattern II in $4(19 \%)$ and pattern 0 in $3(14 \%)$ and mean PSV $(5.6 \pm 1.4 \mathrm{~cm} / \mathrm{s})$ was higher than that of controls $(P=0.026)$.

Conclusions: An increase in both intrathyroidal vascularity and blood velocity was observed in patients with spontaneous hyperthyroidism but not in thyrotoxicosis due to either ingestion of thyroid hormones or to a thyroidal destructive process. The slightly increased vascularity and blood velocity observed in patients with hypothyroid Hashimoto's thyroiditis suggests that thyroid stimulation by either TSH-receptor antibody or TSH is responsible for the increased thyroid blood flow.
\end{abstract}

European Journal of Endocrinology $140452-456$

\section{Introduction}

Hyperthyroidism is associated with hemodynamic changes including high output state, increased heart rate and cardiac contractility, and decreased peripheral resistance $(1,2)$, that are related both to direct cardiostimulatory effects of thyroid hormone and to increased peripheral oxygen consumption $(3,4)$. While cardiac parameters are invariably increased, as assessed by the shortening of systolic and diastolic time-intervals, the increase of systolic and diastolic function and the reduction in the left ventricular ejection fraction (36), regional blood flow distribution is not uniform in hyperthyroidism. For example, blood flow in skeletal muscle, skin, cerebral, and coronary arteries is increased, whereas hepatic blood flow is unchanged $(7-9)$.

Untreated Graves' patients have a hypervascular gland responsible for a thyroid bruit and thrill. The availability of color flow doppler sonography (CFDS), a 
rapid, informative, and non-invasive technique, has recently allowed direct measurement of intrathyroidal blood flow (10-17). Using CFDS it has been shown that intrathyroidal blood flow, which can be quantitated by measurement of peak systolic velocity (PSV), is greatly increased in patients with untreated Graves' hyperthyroidism $(10,11)$. In hyperthyroidism hemodynamic changes are thought to be due to serum thyroid hormone excess. However, in Graves' patients it is not well understood whether thyroidal hypervascularity is related to thyroid hormone excess or to the excessive stimulation of the thyroid gland by TSH-receptor antibody (TRAb). To address this problem, in the present study we have evaluated the intrathyroidal blood flow and PSV by CFDS in patients with various thyroid disorders.

\section{Materials and subjects}

We enrolled in this study 155 consecutive patients seen at our Institution in the period 1995-1997. The main clinical and biochemical features of the subjects are described in Table 1.

\section{Conventional and CFD sonography}

CFDS was performed using an ALU-4 ESAOTE color doppler system (Esaote Biomedicals, Genua, Italy) with a 7.5 $\mathrm{MHz}$ linear electronic transducer. Each patient was first submitted to gray scale sonography; subsequently color flow doppler information was gained. Thyroid volume was measured by ultrasound and calculated by the ellipsoid model (width $\times$ length $\times$ thickness $\times 0.52$ for each lobe) as previously described (11). CFDS images were obtained in the transverse and longitudinal planes and color gain was adjusted to a level not associated with relevant artifacts with the probe repetition frequency at $750 \mathrm{~Hz}$. Color flow imaging was depicted by red and blue spots that indicated the direction of flow toward (red) and away (blue) from the transducer. For quantitative doppler evaluation, the peak systolic velocity (the doppler waveform recorded at the point with the highest frequency shift) was used. Measurements were performed at the level of the intrathyroid arteries, with a sampling volume of $2 \mathrm{~mm}$. Multiple sampling $(n=5)$ was performed to account for variations, and the mean value was expressed. The coefficient of variation of PSV was $8 \%$. The angle correction was not employed due to the tortuosity of small intrathyroidal vessels and their incomplete visualization. PSV values and CDFS pattern were recorded by one of us (FB) who did not know the patients' diagnoses. The possible CFDS patterns were as follows: pattern 0: absent intraparenchymal (or nodular) vascularity or minimal spots; pattern I: presence of parenchymal (or nodular) blood flow with patchy uneven distribution; pattern II: mild increase of color flow doppler signal with patchy distribution (for nodules: mainly peripheral); pattern III: markedly increased color flow doppler signal with diffuse homogeneous distribution, including the so-called 'thyroid inferno' (10) (for nodules: intranodular and peripheral vascularity).

Table 1 Clinical and biochemical features of the subjects.

\begin{tabular}{|c|c|c|c|c|c|c|c|}
\hline Subjects & $\boldsymbol{n}(\mathrm{M} / \mathrm{F})$ & $\begin{array}{c}\text { Mean age } \\
\text { (range) } \\
\text { (years) }\end{array}$ & $\underset{(\mathrm{pmol} / \mathrm{l})}{\operatorname{Serum} \mathbf{F T}_{4}}$ & $\underset{(\mathrm{pmol} / \mathrm{l})}{\text { Serum } \mathbf{F T}_{3}}$ & $\underset{(\mathrm{mU} / \mathrm{l})}{\text { Serum TSH }}$ & $\begin{array}{c}\text { TRAb } \\
(U / l)\end{array}$ & $\begin{array}{c}\text { Positive AbTg/AbTPO } \\
\text { (percent) }\end{array}$ \\
\hline Controls & $24(11 / 13)$ & $40(25-61)$ & $12.2 \pm 0.5$ & $5.5 \pm 0.2$ & $0.9 \pm 0.3$ & Absent & 0 \\
\hline \multicolumn{8}{|l|}{ Hyperthyroidism } \\
\hline Graves' disease & $49(10 / 39)$ & $41(27-64)$ & $42.4 \pm 3.1$ & $23.4 \pm 2.3$ & $<0.03$ & $49.3 \pm 56.5$ & 100 \\
\hline Toxic adenoma & $24(6 / 18)$ & $51(36-69)$ & $32.0 \pm 4.8$ & $11.2 \pm 2.8$ & $<0.03$ & Absent & 0 \\
\hline TSHoma & $5(3 / 2)$ & $41(27-60)$ & $38.6 \pm 3.2$ & $18.6 \pm 2.0$ & $<0.03$ & Absent & 0 \\
\hline \multicolumn{8}{|l|}{ Thyrotoxicosis } \\
\hline Factitia & $7(0 / 7)$ & $61(40-74)$ & $48.6 \pm 11.4$ & $16.7 \pm 2.8$ & $<0.03$ & Absent & 0 \\
\hline Subacute thyroiditis & $12(0 / 12)$ & $34(21-49)$ & $22.6 \pm 4.0$ & $8.3 \pm 1.2$ & $<0.03$ & Absent & 0 \\
\hline \multicolumn{8}{|l|}{ Euthyroidism } \\
\hline Goitrous Hashimoto & $37(8 / 29)$ & $32(18-54)$ & $12.2 \pm 0.7$ & $5.4 \pm 0.6$ & $1.1 \pm 0.5$ & Absent & 100 \\
\hline \multicolumn{8}{|l|}{ Hypothyroidism } \\
\hline Goitrous Hashimoto & $21(5 / 16)$ & $33(21-61)$ & $2.6 \pm 0.8$ & $1.4 \pm 0.7$ & $41.0 \pm 26.0$ & Absent & 100 \\
\hline
\end{tabular}

Normal subjects were recruited among medical personnel of our Institution. Patients with toxic adenoma had a single hot thyroid nodule at scintiscan with absent radioiodine uptake in the extranodular tissue. Patients with thyrotoxicosis factitia had low/suppressed thyroidal $24-h$ radioiodine uptake values $(3 \pm 1 \%)$, normal urinary iodine excretion, and undetectable serum Tg (18). All patients admitted surreptitious thyroid hormone pill intake. Five patients were previously described in detail (16). Patients with TSH-secreting pituitary adenoma (TSHoma) had elevated serum $\mathrm{FT}_{4}$ and $\mathrm{FT}_{3}$ and inappropriately high serum TSH concentration with absent TSH response to i.v. thyrotropin-releasing hormone stimulation and an $\alpha$ subunit/TSH molar ratio greater than 1 . All patients underwent adenomectomy: four patients had a pure TSHoma; in one patient immunohistochemistry revealed a mixed neoplasm with $4 \%$ growth hormone-producing cells. $\mathrm{AbTg}$, anti-thyroglobulin antibody; AbTPO, anti-thyroperoxidase antibody. 


\section{Assays}

Serum free thyroxine $\left(\mathrm{FT}_{4}\right)$, free tri-iodothyronine $\left(\mathrm{FT}_{3}\right)$ (Technogenetics, Milan, Italy), thyrotropin (TSH) (Delphia hTSH ultra Kit; Pharmacia, Turku, Finland), thyroglobulin (Tg) (Sorin Biomedica, Saluggia, Italy), TRAb (TRAK assay; Henning, Berlin, Germany), anti-Tg (Serodia, Tokyo, Japan), and anti-thyroperoxidase (TPO) (Sorin Biomedica) were determined by commercial kits. Normal values in our laboratory were as follows: $\mathrm{FT}_{4}, \quad 8.3-20.5 \mathrm{pmol} / \mathrm{l} ; \mathrm{FT}_{3}, \quad 3.8-8.4 \mathrm{pmol} / \mathrm{l} ; \mathrm{TSH}$, $0.4-3.7 \mathrm{mU} / \mathrm{l} ; \quad \mathrm{Tg}, \quad<3-30 \mathrm{mg} / \mathrm{l}$; anti-Tg, negative; anti-TPO, negative; and TRAb, <5 U/l. Urinary iodine excretion was measured using an autoanalyzer apparatus (Technicon, Rome, Italy). The median urinary excretion of iodine in our area is $110 \mu \mathrm{g} / \mathrm{l}$.

\section{Statistics}

Data are expressed as means \pm s.D. Comparison of parameters among the study groups was performed by the Mann-Whitney U test.

\section{Results}

The results are summarized in Table 2 and in Fig. 1.

Patients with hyperthyroidism had higher PSV values than controls $(P \leq 0.004)$, patients with thyrotoxicosis $(P \leq 0.004)$, and hypothyroid and euthyroid patients with goitrous Hashimoto's thyroiditis $(P \leq 0.0005)$.

Patients with thyrotoxicosis had PSV values which did not differ from those observed in controls and euthyroid patients with goitrous Hashimoto's thyroiditis.

Hypothyroid patients with goitrous Hashimoto's thyroiditis had higher PSV values than euthyroid patients with goitrous Hashimoto's thyroiditis $(P=0.0004)$, controls $(P=0.026)$ and patients with thyrotoxicosis $((P \leq 0.01)$.

\section{Discussion}

The results of the present study confirmed that CFDS is a useful tool to investigate intrathyroidal blood flow and clearly demonstrated that thyroid vascularity and blood flow are mainly dependent on the activation of TSH receptor by TSH, TRAb, or by gain of function mutations of TSH receptor (19), while thyrotoxicosis per se does not cause hemodynamic changes in intrathyroidal vessels. Increased PSV values were observed only in conditions associated with elevated TSH values (mainly central hyperthyroidism due to TSHoma and, to a lesser extent, untreated hypothyroidism due to goitrous Hashimoto's thyroiditis), with the presence of the abnormal TSHreceptor stimulator (TRAb, in untreated Graves' hyperthyroidism) or with gain of function mutations of TSH receptor (toxic adenoma), irrespective of serum thyroid hormone levels (elevated in TSHoma, toxic adenoma and Graves' disease, low in Hashimoto's hypothyroid patients). The fact that the increase in PSV values was modest in hypothyroid patients, and marked in the other two groups, in spite of very high TSH values in the former group, is in keeping with the concept that a responsive (and not damaged) thyroid gland is also required to achieve a substantial increase in thyroid vascularity and blood flow. Autoimmunity per se is unlikely to be the cause of thyroid hypervascularity. In fact, autoimmunity is present in patients with Graves' disease and in patients with Hashimoto's thyroiditis, but hypervascularity is observed only in the presence of TRAb or of increased serum TSH values. Thyroid volume might play some role. However, patients with increased serum TSH levels (TSHoma and hypothyroid patients) had similar thyroid volume (Table 2) but PSV values significantly differed in the two groups (Fig. 1). The importance of thyroid stimulators is supported by recent reports $(20,21)$ showing that TSH can drive thyroidal angiogenesis in

Table 2 Sonography and color doppler characteristics of the subjects.

\begin{tabular}{|c|c|c|c|c|c|c|c|}
\hline \multirow[b]{2}{*}{ Subjects } & \multirow[b]{2}{*}{$n$} & \multirow[b]{2}{*}{$\begin{array}{l}\text { Mean PSV } \\
\quad(\mathrm{cm} / \mathrm{s})\end{array}$} & \multicolumn{4}{|c|}{ CFDS pattern } & \multirow{2}{*}{$\begin{array}{c}\text { Mean thyroid volume } \\
\text { (range) } \\
(\mathrm{ml})\end{array}$} \\
\hline & & & 0 & I & II & III & \\
\hline Controls & 24 & $4.8 \pm 1.2$ & 100 & 0 & 0 & 0 & $10(6-18)$ \\
\hline $\begin{array}{l}\text { Hyperthyroidism } \\
\text { Graves' disease } \\
\text { Toxic adenoma } \\
\text { TSHoma }\end{array}$ & $\begin{array}{r}49 \\
24 \\
5\end{array}$ & $\begin{array}{l}15.0 \pm 3.0 \\
11.0 \pm 2.4 \\
14.8 \pm 4.2\end{array}$ & $\begin{array}{l}0 \\
0 \\
0\end{array}$ & $\begin{array}{r}0 \\
8 \\
20\end{array}$ & $\begin{array}{l}20 \\
70 \\
80\end{array}$ & $\begin{array}{r}80 \\
22 \\
0\end{array}$ & $\begin{array}{l}37(19-63) \\
7.6(1.3-63.7)^{*} \\
23(18-34)\end{array}$ \\
\hline $\begin{array}{l}\text { Thyrotoxicosis } \\
\text { Factitia } \\
\text { Subacute thyroiditis }\end{array}$ & $\begin{array}{r}7 \\
12\end{array}$ & $\begin{array}{l}4.0 \pm 0.8 \\
4.2 \pm 1.1\end{array}$ & $\begin{array}{l}100 \\
100\end{array}$ & $\begin{array}{l}0 \\
0\end{array}$ & $\begin{array}{l}0 \\
0\end{array}$ & $\begin{array}{l}0 \\
0\end{array}$ & $\begin{array}{l}8.5(6-11) \\
7(6-10)\end{array}$ \\
\hline $\begin{array}{l}\text { Euthyroidism } \\
\text { Goitrous Hashimoto }\end{array}$ & 37 & $4.3 \pm 0.9$ & 100 & 0 & 0 & 0 & $23(14-47)$ \\
\hline $\begin{array}{l}\text { Hypothyroidism } \\
\text { Goitrous Hashimoto }\end{array}$ & 21 & $5.6 \pm 1.4$ & 14 & 67 & 19 & 0 & $28(16-49)$ \\
\hline
\end{tabular}

*The value referred to is the volume of the adenoma. 
Figure 1 PSV distribution in the study groups. The horizontal line represents the mean value. Mean PSV in patients with elevated serum TSH or TRAb levels (untreated Graves' disease (TDG), TSHoma, untreated hypothyroidism due to goitrous Hashimoto's thyroiditis (HT hypo)) or with toxic adenoma (TA) was significantly higher than that found in the control group, in patients with thyrotoxicosis factitia (TF) or subacute thyroiditis (SAT) and euthyroid Hashimoto's thyroiditis (HT euthyr). For statistical differences see text. Numbers refer to the number of patients having the same individual PSV value.

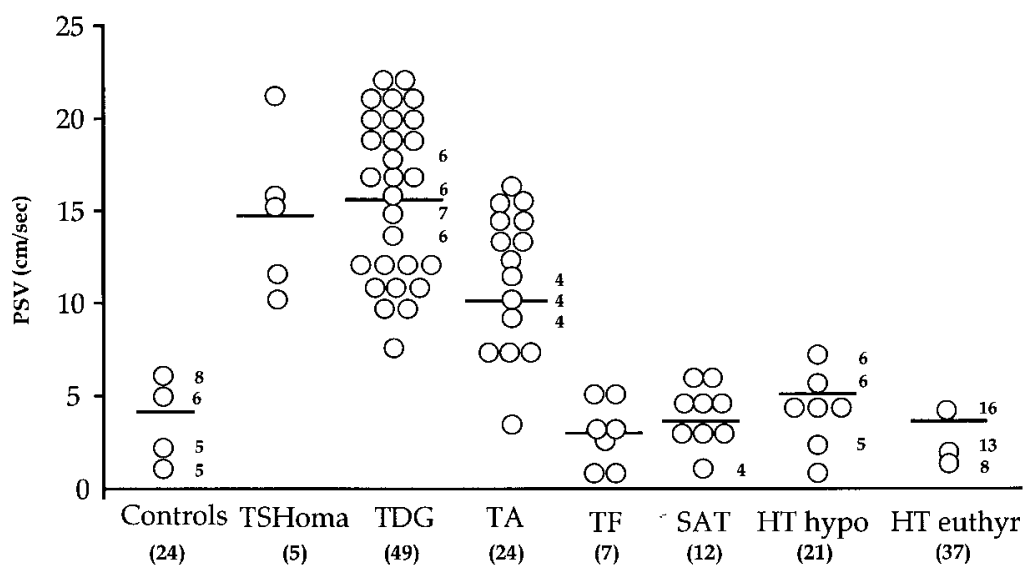

Subjects (n) vitro: this effect might be mediated by the increased expression of growth factors of the vasculotropins and the tyrosine kinase receptor families, which are then released by thyroid follicular cells and in turn act on endothelial cells. It is conceivable that similar effects might be exerted by TRAb. On the other hand, the ineffectiveness of elevated serum thyroid hormones to increase intrathyroidal blood flow might be explained by the recent findings of Diekman et al. (22), who reported that human endothelial cells contain thyroid hormone receptor, but do not produce endothelin in response to thyroid hormone stimulation. Endothelin is a 21 amino acid peptide which is both a vasoconstrictor and a smooth-muscle mitogen, and might have a role in modulating regional blood flow $(23,24)$.

Our data showed that some hypothyroid patients had CFDS pattern II similar to patients with Graves' disease or TSHoma. However, PSV values were only slightly elevated in hypothyroid patients, but greatly increased in the hyperthyroid patients. Thus, CFDS pattern and PSV values are not always superimposable: CFDS pattern II might be found in association, for example, either with a $6 \mathrm{~cm} / \mathrm{s}$ PSV (hypothyroid patients with Hashimoto's thyroiditis) or with $15 \mathrm{~cm} / \mathrm{s}$ PSV (Graves' hyperthyroidism or TSHoma). For these reasons, we would like to suggest that PSV represents a better index of thyroid function than the CFDS pattern. High PSV values are probably indicative of hyperthyroidism, since they reflect a sustained stimulation on a thyroid which is capable of producing and secreting excess thyroid hormone; this does not occur in goitrous Hashimoto's hypothyroidism, in which the sustained stimulation of TSH leads only to a moderate increase in thyroid vascularity and blood velocity, due to the damage of thyroid tissue.

Our data support the concept that spontaneous hyperthyroidism (i.e. a stimulation of the thyroid gland) and not thyrotoxicosis (i.e. a serum increase of thyroid hormone levels) is associated with increased intrathyroidal vascularity. This might be diffuse as in Graves' disease or circumscribed as in toxic adenoma. Thyrotoxicosis due to destructive process of thyroid gland (subacute thyroiditis or type II amiodaroneinduced thyrotoxicosis (17)) or to exogenous ingestion of thyroid hormons (16) are not associated with an increased PSV or CFDS pattern.

Because it is easy, non-invasive and rapid, CFDS and, even more, PSV can provide prompt information on thyroid status. For the interpretation of CFDS pattern and PSV values the examiner must keep in mind that thyroid vascularization depends on thyroid stimulation by TSH or TRAb.

\section{Acknowledgements}

We thank Professor Aldo Pinchera for his continuous encouragement and advice. This work was partially supported by Grants from the University of Pisa (Fondi d'Ateneo) to EM and LB.

\section{References}

1 DeGroot WJ \& Leonard JJ. Hyperthyroidism as a high cardiac output state. American Heart Journal 197079 265-272.

2 Ladenson PW. Recognition and management of cardiovascular disease related to thyroid dysfunction. American Journal of Medicine 199088 638-641.

3 Klein I. Thyroid hormone and the cardiovascular system. American Journal of Medicine 199088 631-637.

4 Polikar R, Burger AG, Scherrer U \& Nicod P. The thyroid and the heart. Circulation 199387 1435-1441.

5 Cohen MV, Schulman IC, Spenillo A \& Surks MI. Effects of thyroid hormone on left ventricular function in patients treated for thyrotoxicosis. American Journal of Cardiology 1981 48 33-38.

6 Woeber KA. Thyrotoxicosis and the heart. New England Journal of Medicine 1992327 94-98.

7 Meyers JD, Brannon ES \& Holland BC. Correlative study of the cardiac output and hepatic circulation in hyperthyroidism. Journal of Clinical Investigation 195029 1069-1072.

8 Rowe GG, Huston JH \& Weinstein AB. Hemodynamics of thyrotoxicosis with special reference to coronary blood flow and 
myocardial oxygen metabolism. Journal of Clinical Investigation $195635372-379$.

9 Kontos HA, Shapiro W \& Mauck HP Mechanism of certain abnormalities of the circulation to the limbs in thyrotoxicosis. Journal of Clinical Investigation 196544 947-951.

10 Ralls PW, Mayekawa DS, Lee KP, Colletti PM, Radin DR, Bosnell WD et al. Color-flow doppler sonography in Graves' disease: 'thyroid inferno'. American Journal of Radiology $1988150781-$ 784 .

11 Fobbe F, Finke R, Rechenstein E, Schleusener H \& Wolf K-J Appearance of thyroid diseases using colour-coded duplex sonography. European Journal of Radiology 1989 9 29-31.

12 Shimamoto K, Endo T, Ishigaki T, Sakuma S \& Makino N. Thyroid nodules: evaluation with color doppler ultrasonography. Journal of Ultrasound Medicine 199312 673-678.

13 Lagalla R, Caruso G, Novara V \& Cardinale AE. Analisi flussimetrica nelle malattie tiroidee: ipotesi di integrazione con lo studio qualitativo con color-doppler. Radiologia Medica 199385 606-610 (In Italian).

14 Vitti P, Rago T, Mazzeo S, Brogioni S, Lampis M, De Liperi A et al. Thyroid blood flow evaluation by color-flow doppler sonography distinguishes Graves' disease from Hashimoto's thyroiditis. Journal of Endocrinological Investigation 199518 857-862.

15 Castagnone D, Rivolta R, Rescalli S, Baldini MI, Tozzi R \& Cantalamessa L. Color doppler sonography in Graves' disease: value in assessing activity of disease and predicting outcome. American Journal of Radiology 1996166 203-207.

16 Bogazzi F, Bartalena L, Vitti P, Rago T, Brogioni S \& Martino E. Color flow doppler sonography in thyrotoxicosis factitia. Journal of Endocrinological Investigation 199619 603-606.

17 Bogazzi F, Bartalena L, Brogioni S, Mazzeo S, Vitti P, Burelli A et al. Color flow doppler sonography rapidly differentiates type I and type II amiodarone-induced thyrotoxicosis. Thyroid $19977541-$ 545.

18 Mariotti S, Martino E, Cupini C, Lari R, Giani C, Baschieri L et al. Low serum thyroglobulin as a clue to the diagnosis of thyrotoxicosis factitia. New England Journal of Medicine 1982 307 410-412.

19 Tonacchera M, Van Sande J, Parma J, Duprez L, Cetani F, Costagliola S et al. TSH receptor and disease. Clinical Endocrinology $199644621-633$.

20 Tseng YC, Lahiri S, Jackson S, Burman KD \& Wartofski L. Endothelin binding to receptors and endothelin production by human thyroid follicular cells: effects of transforming growth factor-beta and thyrotropin. Journal of Clinical Endocrinology and Metabolism 199376 156-161.

21 Viglietto G, Manzo G, Romano A, Paoletti I, Mauriello V, Bruni P et al. TSH and iodine exert opposite effects on thyroid vasculature by modulation of the expression of VEGF and PLGF in rat thyroid gland in vivo and in rat cultured thyrocytes in vitro. Journal of Endocrinological Investigation 199619 (Suppl 6) 49

22 Diekman MJM, Bakker O \& Wiersinga WM. Human endothelial cells in vitro contain $\alpha 1-\mathrm{T} 3$ receptors but do not respond to T3 with endothelin-1 production. Journal of Endocrinological Investigation 199619 (Suppl 6) 9.

23 Vanhovitte PM \& Shimokawa H Endothelium-derived relaxing factor and coronary vasospasm. Circulation $1989801-9$.

24 Plouet J \& Bayard F. Regulations of vasculotropin/vascular endothelial growth factor bioavailability. Hormone Research 199442 14-19.

Received 4 November 1998

Accepted 11 January 1999 